\title{
O caminho do meio para loucos: tradução indireta de nove poemas de Gendun Chopel
}

\author{
Hugo Lorenzetti Neto
}

\begin{abstract}
Resumo: Esta tradução anotada de uma seleção representativa de poemas de Gendun Chopel, monge-andarilho do Tibete e também seu primeiro exilado social, contextualiza a poesia na trajetória incomum dessa vida no início do século XX. Argumento que Chopel era um tibetano progressista, cuja ars poetica, na fronteira entre tradição e modernidade, superando o treinamento clássico em literatura budista, é um contraponto à imagem utópica e irreal do Tibete no mundo ocidental.
\end{abstract}

Palavras-chave: Gendun Chopel; Poesia Tibetana; Modernismo Tibetano

\begin{abstract}
This annotated translation of select and representative poems of Gendun Chopel, Tibet's monk-wanderer and its first social exile, contextualizes the poems in the trajectory of his unusual life in the early twentieth century. I argue that Chopel was a progressive Tibetan whose ars poetica, at the cusp of tradition and modernity despite his classical training in Buddhist literature, is a counterpoint to the utopian-like unreal image of Tibet in the western world.
\end{abstract}

Keywords: Gendun Chopel; Tibetan Poetry; Tibetan Modernism 


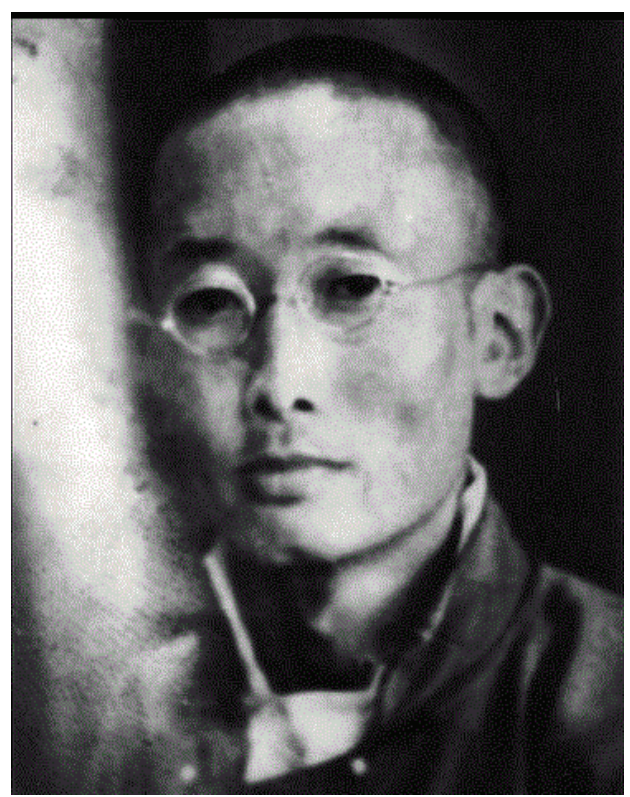

\section{Por que apresentar Gendun Chopel?}

"Não procurem a minha vida em meus poemas", é um verso da poeta indiana de origem goesa Eunice de Souza, de seu poema Autobiográfico. Verso e título podem abrir, numa conversa literária despretensiosa, o caminho para se discutir a relação entre obra e vida dos poetas. O verso de De Souza, alerta para a futilidade de se buscar a vida dentro da obra, como se possível fosse reconstruir aquela fazendo uso desta. E esses são, de fato, conselho e lembrete sensatos para leitores apaixonados, carregados pelo gozo da literatura, como descreve Roland Barthes. No entanto, o que proponho ao preparar estas traduções comentadas é ignorar a sensatez da proposta: faremos um caminho paralelo, lendo partes da obra para buscar nela a relação entre o escrito e o vivido por quem a escreveu. Assim este ensaio apresentará adequadamente um poeta, artista, filósofo e aventureiro tibetano cujos epítetos comuns são iconoclasta, visionário, mestre das artes do amor, herói da cultura tibetana moderna e até santo budista: Gendun Chopel.

Ao apresentar as traduções, e ao fazê-lo de forma a comentar eventos da vida pessoal de Gendun Chopel, explicarei minhas escolhas a tendo como princípio a percepção de que o trabalho desse artista desafia visões pré-concebidas de Tibete e de budismo. Em outras palavras, orienta-me a ideia de que a ars poetica de 
Chopel pode ser apresentada como contraponto à percepção da cultura tibetana e seus agentes como parte da Shangri-La da imaginação ocidental, baseado no romance Lost Horizon de James Hilton: vales e montanhas onde reina harmonia e espiritualidade, a utopia mística isolada do mundo onde a felicidade é permanente. Assim, ao produzir as traduções busquei empregar recursos que encontraríamos entre nossos próprios modernistas, em vez de sugerir tons mais solenes e eruditos. Afinal, Gendun Chopel foi monge e acadêmico budista refinado, mas também frequentou bordeis em Calcutá e construiu uma reputação de extremos, que ele descreveu como "o melhor dos monges, o pior dos mundanos", em poema que aparecerá nesta pequena antologia.

Apresentar Gendun Chopel não é relevante apenas por desafiar o orientalismo, mas também porque sua trajetória de escrita espelha as transformações da modernidade no Tibete. Nascido em 1903 em Amdo, no nordeste da área cultural tibetana, alfabetizado aos três anos de idade e considerado um prodígio, já na infância Chopel foi educado na escrita budista tibetana e no estudo da poesia kavya, prática beletrista rigorosa, de poesia ornamentada e de registros elevados, com origens no sânscrito. Ainda muito jovem, produziu exemplares de diversos gêneros tradicionais, como, por exemplo, o círculo auspicioso: uma tabela de quadrados, dezoito por dezoito, em que cada quadrado recebe uma sílaba, de modo que a matriz possa ser lida como poema em direções diversas. A narrativa heroica sobre o artista conta que Chopel compôs magistralmente dois desses poemas aos doze anos. Para esta seleção escolhi traduzir um poema que não é dessa época, mas se propõe ao jogo no campo formal.

A orfandade ainda na infância e a vida monástica sem grandes lamas apoiadores e mecenas, associadas à inteligência e à percepção fora do comum podem ter levado o jovem e marginal monge a desafiar os rigores hierárquicos e a hipocrisia da vida escolástica, o que se vê na acidez sofisticada de seus insultos a colegas e superiores. E, ainda muito jovem, Chopel entra em contato com a intelectualidade do movimento de independência da Índia, e logo as práticas discursivas modernistas passam a integrar seu próprio programa estético. É então que aparece em seu trabalho a investigação de expressões de ancestralidade, da cultura tibetana anterior à chegada do budismo no Tibete. Um viés da sua produção foi a escrita de textos de corte épico, em prosa e verso, reinventando a estética dos gêneros históricos e ensaísticos, para recontar o tempo e as vidas dos reis do passado anterior à chegada do Padmasambhava, o Guru Rinpoche ao Tibete, trazendo o budismo e a escrita. Esses textos, em verso e prosa, têm sua origem em anotações de viagem em sua própria terra - e a estética dessa produção poderia ser comparada à atitude catalogadora e analítica de Mário de Andrade no Brasil. 
Em outra vertente, sua obra também incorpora expedientes de composição em voga na produção indiana de sua época, o que se vê, por exemplo, em sua lírica erótica, feita após o abandono dos votos monásticos, com base na leitura do Kama Sutra e da experiência pessoal nos bordeis de Calcutá. Mas a modernidade da produção de Chopel não se limitava a forma e modismo: viajante, estudioso, o poeta se interessou por diversos gêneros de escrita: traduções de clássicos indianos como Shakuntala, Bhagavad Gita e Ramayana, tradução do canônico budista Dhammapada, guias de peregrinação, poesia Gendun Chopel também compôs poesia em inglês, parte dela publicada no jornal tibetano Melong, de Kalimpong, cidade indiana nos contrafortes dos Himalaias, próxima ao Reino do Butão e do então independente Reino do Sikkim (hoje um estado da República da Índia).

Essa trajetória literária acompanha a trajetória da vida parte monástica e parte andarilha e mundana de Gendun Chopel. Por essa razão, escolhi os poemas que seguem e os coloquei em percurso não cronológico. A escolha pela apresentação errática se aproxima da própria fortuna da obra de Chopel, que não só nunca publicou seus textos reunidos quando em vida, mas viu parte de sua produção se perder por não haver sido patrocinada por qualquer membro da elite tibetana. Além do infortúnio de origem, quando de seu retorno a Lhassa depois da estada na Índia entre 1938 e 1946, Gendun Chopel teve seus manuscritos e textos publicados, que colecionava numa caixa de metal, apreendidos pelas autoridades da regência do Daktrak Rinpoche, que governou o Tibete enquanto Tenzin Gyatso, o $14^{\circ}$ e atual Dalai Lama, ainda era uma criança. A caixa se perdeu após a prisão, e com ela parte importante do trabalho do autor feito na Índia.

Como Padmasambhava, que espalhou seus escritos por cavernas, lagos e montanhas na paisagem tibetana, a obra de Gendun Chopel se espalhou pela Ásia Meridional, e ainda deve haver textos a serem descobertos. As primeiras reuniões de textos apareceram nos anos 1990, e em 1994 um prêmio literário trienal com seu nome foi criado em Dharamsala, centro do governo tibetano no exílio. E hoje Gendun Chopel é celebrado como um dos grandes heróis da cultura tibetana moderna.

As versões que apresento foram feitas com base nas traduções para o inglês e nas anotações do professor David S Lopez Jr, cujo trabalho é a principal referência teórica deste texto. As anotações de tradução de Lopez são base para experiências de tradução que empreendi para apresentar o poeta. Assim, a distância entre estes versos em português seria descrita continuando por alguns versos o seguinte quarteto de Gendun Chopel: 
The distance between a promise and a contract is far.

The road from $\mathrm{U}^{1}$ to Amdo is very long.

From Magadha to Tibet is most distant.

From actual Sanskrit to Tibetanized Sanskrit is farther than that.

A distância entre uma promessa e um acordo é grande.

A estrada de U a Amdo é muito longa.

De Magadha ao Tibete, a maior distância.

De sânscrito verdadeiro a sua versão tibetana, maior ainda.

No entanto, traduzir Gendun Chopel, ainda que indiretamente, é conduzir sua obra pelo caminho de sua própria ética viajante e cosmopolita, e exercer o mesmo ofício que ele, entre tantos ofícios, exerceu. Para o público brasileiro, em especial aquele ainda não familiarizado com a cultura tibetana, conhecer Chopel desperta a percepção de que o Tibete e sua cultura são plurais, vivos; que há questões e respostas sobre a realidade, compartilhada globalmente ou local, comuns em épocas diferentes; que o Tibete real, de monges loucos e caminhos do meio desajustados, é muito mais interessante que o estereótipo monótono de Shangri-La que se lhe atribui.

\section{O caminho do meio para loucos}

Em 1946, depois de quase doze anos de viagens à Índia e ao Sri Lanka, Gendun Chopel regressou a Lhassa, e, poucos meses depois da chegada, foi preso pelo governo do jovem Dalai Lama, por ordem do regente, Daktrak Rinpoche. Inicio a trajetória poética neste ponto por me parecer um momento de impacto contra as possíveis visões de nossa sociedade sobre o Tibete: um poema produzido durante cumprimento de pena após prisão ordenada pelo governo de um grande líder político e espiritual oriental, articulada, provavelmente, pela Comissão Britânica residente na capital tibetana, cujo primeiro quarteto, como se afirma, foi encontrado escrito no colchão da cela habitada pelo poeta. A produção de Chopel não cessou durante o período em que esteve encarcerado ao pé do Palácio de Potala, residência de inverno dos Dalai Lamas desde o século XVII até 1959,

1 Referência a U-tsang, província de onde o Dalai Lama governava o Tibete. 
e embora ele tivesse à disposição meios para escrever, a hipótese da escrita no colchão não é absurda.

In the jungle where the frightful roar resounds

Of the stubborn tiger drunk on the blood of envy,

The honest little child is left all alone.

May the wise think of him with compassion.

Though fools may not follow you,

Never follow fools.

That is the first vow of the wise.

Keep it though it costs you your life.

Na selva onde ressoa o assustador rugido

Do tigre obstinado ébrio do sangue da inveja

O menininho honesto está abandonado.

Que os sábios nele pensem com compaixão.

Por mais que os tolos não te sigam

Nunca siga os tolos.

É o primeiro juramento dos sábios.

Sustenta-o por mais que te custe a vida.

A possibilidade de que realmente o primeiro quarteto tenha sido encontrado escrito no colchão da cela onde seu autor ficou preso é um dos elementos atrelados às condições de produção do poema (que são quase sempre, para quase todos os textos, muito difíceis de traçar) que colaboram para a construção da mitologia de herói moderno em torno de Gendun Chopel. Comprovável ou não, o fato é coerente com a biografia do monge: denunciar a espiritualidade interesseira, a afetação de conhecimento e marcar e ser marcado pelas experiências e pelos lugares onde foram vividas é traço de sua produção. Concentram-se, também, nesse curto poema, temas que atravessam sua obra: a crítica ácida à hierarquia do poder par a par com a reafirmação de devoção e fidelidade aos princípios espirituais budistas.

Neste poema, Chopel faz um comentário à situação política tibetana na regência do Daktrak Rinpoche, tutor do $14^{\circ}$ e atual Dalai Lama, na época ainda criança. Escolhi o traduzir "little child" como "menininho", para entregar uma versão de interpretação mais fechada, considerando a distância desses fatos para a maior 
parte dos leitores brasileiros. Além disso, escolhi o diminutivo afetivo para aproximar poeta e personagem e reforçar o sentimento de compaixão expresso no poema. Acredita-se que os Dalai Lamas são reencarnações sucessivas de Avalokitesvara, o Bodhisattva da Compaixão. Aprofundar a expressão da compaixão do monge, ecoada na súplica pelo mesmo sentimento aos sábios, constrói-se uma inversão expressiva: ter compaixão da própria manifestação espiritual da compaixão. Isso tudo agrava a maldade do tigre obstinado e invejoso, mais ainda se considerada a tradução de Daktrak: "tigre de pedra".

$\mathrm{Na}$ segunda estrofe, escolhi conjugar os verbos na segunda pessoa do singular, de modo a expressar alguma solenidade ou reverência, para que a interpelação possa ter destinatário ambíguo: o jovem Dalai Lama ou o próprio leitor.

Liberado pouco antes do prazo de cumprimento da pena, Gendun Chopel entrou em uma espiral desintegradora: miserável e consumido pela cirrose, morreu pouco depois da invasão de Lhassa pelo Exército de Liberação Popular Chinês. Sua poesia do período do cárcere apontava para esse movimento, como quando ele escreve:

A virtuous family, the lineage of monks, the way of a layman,

A time of abundance, a time of poverty,

The best of monks, the worst of laymen,

My body has changed so much in one lifetime.

Estirpe virtuosa, a linhagem dos monges, o caminho do leigo

Anos de abundância, anos de miséria

O melhor dos monges, o pior dos mundanos

Meu corpo mudou tantas vezes no tempo de uma vida.

Neste poema de pares contrastantes (monge/mundano; abundância/miséria), Gendun Chopel rememora e resume sua vida como o caminho de meio do louco, entre a fortuna e o infortúnio. Lopez anota que o que ele escolheu traduzir como "family" era originalmente a palavra para dizer "osso", que tem também função semântica de linhagem. No uso específico no verso há polissemia. O termo pode se referir a laços sanguíneos, a laços de tradição monástica e também às sucessivas reencarnações. O tradutor afirma oscilar entre "blood" e "family", enquanto eu mesmo oscilei entre família e estirpe, e escolhi o segundo, por me parecer mais abrangente. 
A escolha por "anos" em lugar de "tempo", fiz pensando em expressões como "anos dourados", ou "anos de chumbo", por me parecer escolha mais corriqueira que época ou tempo, e menos duradoura que era. Variei as traduções de layman/laymen para incluir no poema a nuance institucional religiosa (leigo, em oposição a monge), lembrando que de fato Chopel renunciou aos votos monásticos antes de partir para a Índia ou logo depois de lá chegar. Na segunda ocorrência, decidi dar nuance de pecado, de homem em falta com princípios morais, mais que apenas uma palavra que se referisse unicamente à desconexão institucional. Esse significado mais intenso separei para a segunda estrofe porque é o momento do lamento. $\mathrm{O}$ uso de mundano prolonga a aliteração do fonema $/ \mathrm{m} /$ (miséria, melhor, monge, mundano), que, no contexto, ecoa o lamento que é tema do texto.

Ainda na temática da fortuna da vida e da obra, o poema que segue foi incluído na obra "A Crônica Dourada", grande projeto de literatura de viagem, formado por sequências em gêneros textuais diferentes, incluindo traduções, ensaios e poesia, num volume de mais de 600 páginas, que versa sobre o que Chopel conheceu na Índia, no Sri Lanka e no próprio Tibete.

Walking with weary feet to the plains of the sandy south, Traversing the boundary of a land surrounded by the pit of dark seas, Pulling the thread of my life-precious and cherished-across a sword's sharp blade,

Consuming long years and months of hardship, I have somehow finished this book.

Although there is no one to beseech me

With mandates from on high or mandalas of gold, I have taken on the burden of hardship alone and written this, Concerned that the treasury of knowledge will be lost.

Though terrified by the orange eye of envy

In the burning flame of those bloodthirsty for power, Accustomed to the habit of gathering what I have learned, My mind is attached to reasonable talk.

If it somehow enters the door of a wise person, intent on learning, Then the fruit of my labor will have been achieved. 
For the smiles of the stupid and the approval of the rich, I have never yearned even in my dreams.

When this ink-stained body's need for food and drink is finished,

When this collection of bones-its thread of hope for gain and honor snapped-is scattered,

Then may the forms of these letters, a pile of much learning amassed through hardship,

Reveal the path of vast benefit in the presence of my unseen friend

Caminhando com pés cansados até os planaltos do sul arenoso,

Cruzando os limites de uma terra cercada pelo abismo de mares escuros,

Passando o fio de minha vida - precioso e amado - pela lâmina afiada de uma espada,

Consumindo longos anos e meses de sofrimento, por sorte terminei este livro.

Embora sem ter quem me peça

Com mandados de altas mandalas de ouro

Carreguei o sofrido fardo sozinho e escrevi

Receoso de que o tesouro do conhecimento se perca.

Ainda que aterrorizado pelo olhar alaranjado da inveja

Na chama ardente dos sedentos por poder,

Acostumado ao hábito de colecionar o que aprendi,

Minha mente se une à fala razoável.

Se por acaso adentrar pela porta de uma pessoa sábia, desejosa de aprender,

Então o fruto de meu trabalho terá sido alcançado.

Pois aos sorrisos dos imbecis e à aprovação dos ricos

Nunca almejei, nem mesmo em meus sonhos.

Quando a urgência por comida e bebida deste corpo manchado de tinta acabar, Quando esta coleção de ossos - roto seu fio de esperança por ganho honra - se espalhar,

Então que as formas destas letras, uma pilha de muito saber acumulado com sofrimento, Revele o caminho do benefício vasto na presença do amigo nunca visto. 
Nesse poema, Chopel demonstra reconhecer o valor de sua própria obra. Na verdade, na poesia, Chopel não questiona o valor de sua produção, nem artística nem filosoficamente. Seu temor não era exatamente de escrever insensatezes, consciente que era de sua própria genialidade, mas de que sua obra desaparecesse, dada sua própria fragilidade de inserção social no meio intelectual de sua época. Gendun Chopel não teve grandes mecenas em vida. Seus trabalhos extensos, como aquele de onde se extraiu o poema, não receberam o devido tratamento editorial à época, por mais que fossem reconhecidos por seus pares como obras de interesse. Assim, com publicações esporádicas como as feitas no jornal tibetano Melong, publicado na cidade de Kalimpong, a obra e o pensamento de Chopel correu, de fato, risco de desaparecimento, e esse risco era temática importante de suas composições.

O tema se desenvolve por meio de progressão argumentativa simples: na primeira estrofe, apresenta-se o objeto; um livro escrito em meio a dificuldades, expressas comon sucessão de metáforas referentes a viagem e travessia arriscada. Nas duas estrofes seguintes, expõem-se os obstáculos objetivos (falta de recursos e inveja), e as virtudes usadas para superá-los (persistência e cultivo da mente). As virtudes pertencem também ao catálogo budista. Nas duas estrofes finais, o augúrio desejado para a obra: atingir aos sábios desconhecidos desejosos de conhecimento para fazer-lhes as revelações que ela contém. Mantive estruturas e as escolhas o mais próximas possível daquelas de Lopez, já que no material usado para este exercício, pouco comentário havia a respeito da forma desse poema.

Como anotação cabe marcar que "plain", traduzi como "planalto", tomando como referência provável o planalto meridional do Tibete, que separa Amdo de Lhasa e da Índia, a terra cercada por abismos de mares escuros. A sucessão de metáforas se organiza numa travessia entre esses pontos, de modo que a escolha do acidente geográfico me parece mais adequada que, por exemplo, planície. É de se comemorar que em português tenha sido possível aproveitar a sonoridade do trecho "mandados de altas mandalas de ouro". E, finalmente, embora não seja questão de tradução, chamo atenção aqui para o uso do laranja, cor do fogo, como cor de inveja que consome.

Gendun Chopel foi educado para escrever formas tradicionais da poesia budista tibetana e, sobretudo, da kavya, poesia bem ornamentada de origem na literatura em sânscrito. Um número considerável de poemas segue, no original, forma tradicional fixa, como os poemas alfabéticos, que têm as primeiras letras de cada verso em ordem alfabética, ou o círculo auspicioso, já mencionado na primeira parte deste ensaio. A maior parte dos versos metrificados de Chopel tem 
oito sílabas, embora selam comuns os heptassílabos, eneassílabos e decassílabos. No ensino de poesia, Gendun Chopel era partidário de treinar seus alunos primeiro na escrita de versos mais curtos, já que os mais longos eram considerados mais simples. O pensamento formal preciso aparecer reinventado na produção modernista de Chopel, em jogos de composição de inspiração tradicional ou kavya propostos pelo próprio poeta. No texto que segue, de acordo com Lopez (2009), os versos das duas primeiras estrofes iniciavam com cada um com um número, de modo que se estabelecesse uma contagem de um a oito no início de cada verso. Encerrada a contagem, as estrofes finais seguiam outros padrões: a penúltima estrofe tinha cada um de seus versos iniciados por um ponto cardeal, enquanto a última tinha seus versos iniciados pela palavra vasto. Lopez afirma haver traduzido de forma a se manter fiel ao conteúdo. Como exercício, decidi seguir a proposta inicial de Chopel, tentando manter o mais próximo possível dos significados na versão inglesa.

The one door of entry into the realm of peace is

The two truths: profound doctrine, stainless path.

You reveal this to the assembly of disciples of the three lineages.

I bow to you, the Buddha, four-bodied lord.

All beings included in the five lineages

Depend on the path of the six perfections.

Relying constantly on all the qualities of the seven jewels

May they attain the body free of the eight extremes of elaboration.

This way to travel to the land of India in the south

Reaching to the ends of the oceans of the east and west,

This lamp raised in the darkness of the west

Was written for the people of Tibet in the north.

The cities like vast oceans,

The stūpas like vast mountains,

To see so many vast sights

Come but once to this vast land of India.

Uma é a porta de entrada do reino da paz, que são

Duas verdades: doutrina profunda e caminho imaculado. 
Três são as linhagens de discípulos em assembleia a quem isso se revela.

Quatro corpos do Buda, a vós me curvo.

Cinco linhagens incluem todos os seres

Seis são as perfeições de cujos caminhos eles dependem.

Sete joias em cujas qualidades todas confiar constantemente

Oito extremos de elaboração de que essas joias hão de libertar o corpo.

Sul é a direção que leva às terras da Índia

Leste e oeste os oceanos cujos fins elas alcançam,

Oeste escuro onde se ergueu esta lâmpada para o

Norte onde o povo do Tibete recebe seus escritos.

Vastos oceanos feitos de cidades,

Vastas montanhas de estupas,

Vastos numerosos panoramas para se ver

Vasta terra da Índia aonde deves vir sem demora.

Para fazer o enjambement entre os primeiros dois versos, a inversão fez que um período simples, com predicado nominal no texto fonte fosse transformado em subordinação adjetiva. No terceiro verso, foi necessária nova subordinação, dada a necessidade de trazer "linhagens" para perto do numeral. "You", referência ao Buda nesse verso, tornou-se sujeito indeterminado, de modo que a referência ao Iluminado surge apenas no vocativo do verso seguinte.

O recurso à subordinação ocorre também na segunda estrofe, onde, no segundo verso, também foi preciso um anafórico para estabelecer inequivocamente o vínculo entre "seres" e "dependem".

$\mathrm{Na}$ terceira estrofe, mudei o sujeito do verbo alcançar, provocando mudança de sentido: a terra alcança os oceanos no lugar do viajante destinatário do poema, expresso na versão fonte. Em seguida, o direcionamento dos escritos é explicitado pelo verbo receber, o que desloca o sentido original: os textos parte e chegam a algum lugar, mas nada se fala sobre que sejam recebidos, a não ser na minha versão.

Ao inverter as comparações nos dois primeiros versos da última estrofe, optei por aprofundar a equivalência em metáfora, em vez de utilizar estruturas mais complexas que alongariam demasiadamente os versos. No verso final, o 
imperativo perdido da versão em inglês é substituído pelo verbo dever. Numa primeira tentativa, traduzi o verso como "Vasta terra da Índia aonde deve-se vir sem demora". A versão ignorava desnecessariamente a interlocução, e por isso a convocação para a visita parecia menos apelo e mais recomendação genérica. Conjugando o verbo, a recomendação passa a ser individual, apelo íntimo ao leitor. Como na versão fonte, o destinatário do poema aparece apenas no verso final, exigindo releitura para reacomodar o texto como interpelação.

A proposta que me fiz de seguir as descrições do original rendeu-me um exercício prazeroso de encaixe de sentidos e formas sintáticas, e de escolhas e perdas. Imagino essa tarefa como atividade que me aproxima como tradutor do trabalho original: um quebra-cabeças de formas, exercício de concentração na linguagem.

Seria injusto com o leitor brasileiro, numa apresentação de um herói santo budista e mundano rebelde, deixar de traduzir de sua poesia erótica, de que são exemplos os dois poemas que seguem. Gendun Chopel estudou a literatura erótica do sânscrito, e, durante sua estada em Calcutá, frequentou os bordeis e a vida noturna da cidade.

Because men and women are so different, If they were not joined by coupling, The world would be split into two factions Always in quarrels and war.

Porque homens e mulheres são tão diferentes,

Se não forem unidos pela cópula,

O mundo seria cindido em duas facções

Sempre em disputa e guerra.

O ato sexual é tratado aqui como fundamento da vida política, e sua formulação remete a escritos políticos tradicionais budistas, como o Arthashastra, de Chanakya, professor, filósofo, economista, jurista e conselheiro real e articulador político da acensão da dinastia Maurya e queda da dinastia Gupta, no século III A. C. Especulo que Gendun Chopel talvez tenha tido acesso ao Arthashastra, ou pelo menos à história de Chanakya, que faz parte dos cânones budistas do Sri Lanka. Com essas observações em mente, procurei manter registro elevado e solene ao realizar a tradução, o que não esconde aspectos cômicos do texto. 
First kiss the arms and under the arms

Then slowly kiss the belly.

Becoming more intoxicated, kiss the thighs and vulva;

Draw the streams of the channels into the sea.

Primeiro beijar os braços e sob os braços

Depois lentamente beijar a barriga

Intoxicando-se mais, beijar os quadris e a vulva

Conduzir as correntezas dos canais para o mar.

Este outro poema erótico instrui objetivamente nos três primeiros versos sobre como fazer sexo, e encerra numa metáfora para o orgasmo, que deve ser conduzido pelo amante que beija o corpo feminino. Escolhi usar o infinitivo para as instruções, como em um livro de receitas, para diminuir os efeitos de interpelação do imperativo em português, evitar a escolha entre segunda e terceira pessoa do singular para esse modo verbal, e permitir a leitura do texto como rememoração e solilóquio, para além de instruções.

De modo algum tratar os textos como instrucionais é indevido; o problema é tratá-los só assim. Porém, de fato, Gendun Chopel trabalha os temas do Kama Sutra, que neste poema é citado diretamente:

Like a timid thief eating a meal in hiding,

To churn in and out and then ejaculate

Silently and quietly in a darkened bed,

This is not the true celebration of passion.

Thus one should know desire's sixty-four arts,

Which offer diverse flavors of bliss,

Like those of molasses, milk, and honey,

To the passionate man and woman.

Como um ladrão tímido comendo escondido

Enfiar e tirar e em seguida ejacular

Silenciosa e sossegadamente em uma cama no escuro

Não é a celebração verdadeira da paixão 
Assim, deve-se conhecer as sessenta e quatro artes do desejo, Que oferecem sabores de êxtase variados

Como aqueles de melado, leite e mel, À mulher e ao homem apaixonados.

As sessenta e quatro artes do desejo é referência direta, nada codificada, ao Kama Sutra. Escolhi separar os movimentos do sexo expressos por "churn in and out" em dois verbos, para aproximar o poema do palavreado de sexo em português do Brasil. Poderia ter usado "botar para dentro e para fora", mas além de alongar demasiadamente o verso, "botar para fora" remeter a vômito. Numa primeira versão usei "socar", no lugar de "enfiar", e decidi pelo segundo por ser mais suave, menos pornográfico que o primeiro. Para "bliss" escolhi "êxtase", palavra também usada em contexto religioso. Traduzi "quietly" como "sossegadamente" para aproveitar a aliteração com os fonemas /s/ e /m/, e criar, assim, paisagem sonora sussurrada e gemida, condizente com o tema do poema.

Para concluir este ensaio, selecionei um dos poemas originalmente escritos em inglês. Para Gendun Chopel era impossível se expressar poeticamente em idioma que não fosse nativo. Ainda assim, com alguma ajuda de seus interlocutores indianos e ocidentais, Chopel produziu exemplares graciosos, de proximidade muito reconhecível com a tradição de "nature poetry". Para esta seleção, no entanto, escolhi o que pode ter sido sua primeira composição em inglês. Optei pela sequência de diminutivos para acentuar a singeleza do texto. E, para que as últimas palavras do ensaio mostrem a curiosidade, a autenticidade espiritual e encerro-o com poema e tradução, já comentados.

Look at God by two small eyes

Listen to him by two small ears

Serve him by two small hands

Go to the church by two small feet

Tell the truth by a small tongue

Be loved by a small heart

Praise God for ever and pray to him.

Olhe para deus com dois olhinhos

Escute-o com dois ouvidinhos

Sirva-o com duas mãozinhas 
Vá para a igreja com dois pezinhos

Diga a verdade com a sua linguinha

Receba o amor com seu coraçãozinho

Louve a Deus e reze para ele.

\section{Referências bibliográficas}

BRITTO, Paulo Henriques. A Tradução Literária. Rio de Janeiro: Civilização Brasileira, 2012.

CHOPEL, Gendun. trad. e ed. LOPEZ Jr, Donald S. In the Forest of Faded Wisdom: 104 Poems by Gendun Chopel. Chicago: The University of Chicago Press, 2009.

DE SOUZA, Eunice. A Necklace of Skulls, New Delhi: Penguin Books, 2012.

HILTON, James. Lost Horizon. UK: Macmillan, 1933.

LARANJEIRA, Mário. Poética da Tradução. São Paulo: Edusp, 2003.

LOPEZ Jr, Donald S. The Madman's Middle Way: Reflections on Reality of the Tibetan Monk Gendun Chopel, Chicago: The University of Chicago Press, 2005.

Hugo Lorenzetti Neto é escritor, tradutor e diplomata. Serviu em Nova Delhi entre 2014 e 2017, onde atuou como chefe do setor cultural da embaixada brasileira. Nesse período aprofundou suas leituras da produção moderna e contemporânea das literaturas da Ásia Meridional. Atualmente reside em Recife e cursa o mestrado em Escrita Criativa na Universidade Federal do Rio Grande do Sul. Seus volumes de poesia "24" e "A máquina extraordinária” serão publicados pela Editora Zouk em agosto. 